\title{
Influência do tratamento térmico do caldo de cana no desenvolvimento do processo fermentativo e na composição química da cachaça
}

\author{
Influence of the heat treatment of sugarcane juice on the fermentative process and \\ chemical composition of cane spirit
}

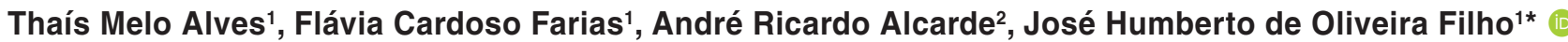 \\ 1 Instituto Federal de Educação, Ciência e Tecnologia do Triângulo Mineiro (IFTM), Setor de Agroindústria, Uberaba - MG - Brasil \\ 2 Universidade de São Paulo (USP), Departamento de Agroindústria, Alimentos e Nutrição, Piracicaba/SP - Brasil
}

\section{${ }^{*}$ Corresponding Author:}

José Humberto de Oliveira Filho, Instituto Federal de Educação, Ciência e Tecnologia do Triângulo Mineiro (IFTM), Setor de Agroindústria, Rua João Batista Ribeiro, 4000, Distrito Industrial II, CEP: 38064-790, Uberaba/MG - Brasil, e-mail: josehumberto@iftm.edu.br

Cite as: Influence of the heat treatment of sugarcane juice on the fermentative process and chemical composition of cane spirit. Braz. J. Food Technol., v. 21, e2017126, 2018

Received: Aug. 10, 2017; Accepted: June 21, 2018

\section{Resumo}

A introdução de diferentes linhagens de microrganismos nas fermentações destinadas à produção de cachaça, decorrente das alimentações sucessivas de caldo, pode contribuir com o desenvolvimento de diferentes classes de microrganismos, comprometendo a atividade metabólica das leveduras e a condução do processo fermentativo. Assim, o objetivo do presente estudo foi avaliar a influência do tratamento térmico do caldo de cana nas características tecnológicas e microbiológicas do substrato, e os seus reflexos na condução do processo fermentativo e na qualidade química da cachaça. Para tanto, o caldo foi submetido a tratamento térmico à temperatura de $90^{\circ} \mathrm{C}$ por 5 minutos, para então serem quantificadas as concentrações de bactérias láticas, leveduras totais e leveduras não Saccharomyces. As fermentações foram conduzidas em cinco ciclos fermentativos, utilizando-se mosto de caldo de cana tratado e não tratado termicamente. O processo foi monitorado por meio das análises de viabilidade celular e de brotos, e do índice de brotamento, enquanto as populações de leveduras totais e não Saccharomyces foram quantificadas no fermento reciclado. Ao término das fermentações, foram determinados o pH, a acidez total titulável, o teor alcoólico e os açúcares redutores residuais totais dos vinhos, sendo estes destilados em alambique de cobre para a quantificação da composição química da cachaça. O tratamento térmico possibilitou a inativação dos microrganismos do caldo, sem comprometer as suas características físico-químicas. A viabilidade celular foi reduzida para as fermentações conduzidas com caldo não tratado termicamente, porém as características físico-químicas dos vinhos não foram afetadas. Os destilados provenientes de fermentações conduzidas com caldo não tratado apresentaram maiores níveis de acidez volátil e ésteres, ao final do quinto ciclo. As concentrações de álcoois superiores e furfural foram elevadas para ambos os tratamentos no primeiro e quinto ciclo, respectivamente.

Palavras-chave: Inativação térmica; Fermentação alcoólica; Leveduras; Microrganismos; Viabilidade celular; Compostos secundários.

\section{Abstract}

The introduction of different strains of microorganism in the fermentations destined for the production of cane spirit, due to successive broth feeds, may contribute to the development of different classes of microorganism, compromising the metabolic activity of the yeasts and hence the direction of the fermentative process. Thus the present study aimed to evaluate the influence of the heat treatment of the sugarcane juice on the technological and microbiological characteristics of the substrate and their effects on the direction of the fermentative process and the chemical quality of the cane spirit. The juice was treated at $90^{\circ} \mathrm{C}$ for 5 minutes and the concentrations of lactic bacteria, total yeasts and non-Saccharomyces yeasts then quantified. Five fermentative cycles were carried out using heat treated and untreated sugarcane juice musts. The process was monitored via cell viability and bud production and determination of the budding index, and the total and non-Saccharomyces yeast populations quantified in the recycled yeast. At the end of the fermentations, the $\mathrm{pH}$, total titratable acidity, alcohol 
Influência do tratamento térmico do caldo de cana no desenvolvimento do processo fermentativo e na composição química da cachaça

Alves, T. M. et al.

content by volume and total residual reducing sugars of the wines were determined, these being distilled in a copper still for quantification of the chemical composition of the cane spirit. The heat treatment allowed for inactivation of the microorganisms in the juice without compromising their physicochemical characteristics. The cell viability was reduced when the fermentations were carried out with untreated juice, although the physicochemical characteristics of the wines were not affected. The distillates from fermentations carried out with untreated juice showed higher levels of volatile acidity and esters at the end of the 5th cycle. The concentrations of higher alcohols and furfural were elevated for both treatments in the 1st and 5th cycles, respectively.

Keywords: Heat inactivation; Alcoholic fermentation; Yeasts; Microorganisms, Cell viability; Secondary compounds.

\section{Introdução}

No Brasil, a Instrução Normativa n. ${ }^{\circ} 13$ de 2005 define cachaça como a bebida com graduação alcoólica entre 38 e $48 \%$ v.v $v^{-1}$ a $20{ }^{\circ} \mathrm{C}$, obtida pela destilação do mosto fermentado de caldo de cana-de-açúcar com características sensoriais peculiares, podendo ser adicionada de até $6 \mathrm{~g} . \mathrm{L}^{-1}$ de açúcares, expresso em sacarose (BRASIL, 2005a).

Nas fermentações destinadas à produção de cachaça, é produzida uma variedade de compostos responsáveis pelo desenvolvimento do perfil químico e sensorial da bebida. Dentre estes, estão os álcoois (1-Propanol, 2-Metil-1-propanol, 2-Metil-1-butanol, etc), acetatos (acetato de etila), ácidos voláteis (ácido acético, propiônico e butírico), aldeídos (acetaldeído), entre outros (DUARTE et al., 2013).

Uma diversidade de microrganismos pode se desenvolver nesta etapa, decorrente das alimentações sucessivas de caldo e das condições intrínsecas do processo $(\mathrm{pH}$, concentração de etanol, disponibilidade de substrato e temperatura), sendo estes responsáveis pela produção dos compostos químicos que caracterizam o destilado (BADOTTI et al., 2010a; DUARTE et al., 2013; GOMES et al., 2010; MUTTON et al., 2014).

A presença de microrganismos indesejáveis na fermentação alcoólica pode ocasionar transtornos operacionais, resultando em consumo de açúcares e nutrientes, redução da viabilidade celular das leveduras, floculação do fermento e liberação de metabólitos tóxicos. Tal situação pode comprometer o desenvolvimento do processo e a qualidade da cachaça (SOUZA; MUTTON, 2004; BASSO et al., 2008; DUARTE et al., 2011; OLIVEIRA FILHO et al., 2016).

O controle dos microrganismos existentes no processo fermentativo é extremamente importante, pois contribui com a manutenção do número de células viáveis de leveduras, a menor síntese de ácidos orgânicos e o aumento da produção de álcool no vinho (MUTTON et al. 2014).

O tratamento térmico é uma operação unitária que visa a inativação enzimática e a redução da população microbiana dos alimentos (BARUFFALDI; OLIVEIRA, 1998), sendo uma alternativa para o controle dos microrganismos característicos do caldo de cana-de-açúcar (OLIVEIRA et al., 2007).

Neste contexto, o presente estudo teve o objetivo de avaliar a influência do tratamento térmico do caldo de cana sobre as características físico-químicas e microbiológicas do substrato e os seus reflexos na condução do processo fermentativo e na formação dos compostos químicos da cachaça.

\section{Material e métodos}

\subsection{Condução do experimento}

Para a condução do experimento, utilizou-se a variedade de cana-de-açúcar SP14-7006, cultivada na região de Uberaba-MG, na safra 2016/2017, colhida manualmente, sem queima da palha e despontada.

\subsection{Tratamento térmico do caldo e preparo do mosto}

Após colheita dos colmos de cana, o caldo foi extraído em moenda convencional e filtrado, sendo este caracterizado como caldo não tratado (T1). O caldo tratado (T2) foi submetido ao tratamento térmico a $90{ }^{\circ} \mathrm{C}$ por 5 minutos, após filtração. Em seguida, o mosto foi preparado a $16^{\circ}$ Brix com adição de água destilada.

\subsection{Análises do caldo de cana-de-açúcar}

Os caldos foram analisados quanto aos parâmetros: 'Brix (CONSECANA, 2006); pH por leitura direta em pHmetro digital Digimed DMPH - 2, com temperatura corrigida em $25^{\circ} \mathrm{C}$; açúcares redutores totais (LANE; EYNON, 1934); acidez total titulável pela titulação do caldo com $\mathrm{NaOH} 0,05 \mathrm{~N}$, sendo os resultados expressos em $\mathrm{g} \mathrm{H}_{2} \mathrm{SO}_{4} \mathrm{~L}^{-1}$ (COPERSUCAR, 2001), e contagens de bactérias lácticas (CECCATO-ANTONINI, 2010), leveduras totais (CECCATO-ANTONINI, 2010) e leveduras não Saccharomyces (WALTERS; THISELTON, 1953, modificado por MORRIS; EDDY, 1957 apud CECCATO-ANTONINI, 2010).

\subsection{Condução da fermentação alcoólica}

As fermentações foram conduzidas em batelada, com recuperação do fermento por decantação, durante cinco ciclos fermentativos, em dornas de aço inoxidável de fundo cônico, com capacidade total de 22 litros. Em cada tratamento, foram adicionados 14 litros de mosto a $16^{\circ}$ Brix, divididos em duas alimentações de 7,0 L, com adição da segunda alimentação após 60 minutos de início do processo fermentativo. Utilizaram-se leveduras comerciais da espécie Saccharomyces cerevisiae, com adição de $30 \mathrm{~g}$ de células por litro de mosto, constituindo-se aproximadamente $10^{7}$ UFC. $\mathrm{mL}^{-1}$. Ao término de cada ciclo 
Influência do tratamento térmico do caldo de cana no desenvolvimento do processo fermentativo e na composição química da cachaça

Alves, T. M. et al.

( ${ }^{\circ}$ Brix igual a zero), foi aguardada a decantação do fermento para separação do vinho e reaproveitamento do inóculo.

\subsection{Caracterização microbiológica dos processos fermentativos}

A viabilidade de células e brotos e o índice de brotamento das leveduras foram analisados 30 minutos após a segunda alimentação de cada batelada proveniente do primeiro ao quinto ciclo fermentativo, utilizando a Câmara de Neubauer para a contagem de células no mosto em fermentação (SILVA et al., 2003).

Para avaliar a população de leveduras no fermento reciclado de cada um dos cinco ciclos fermentativos, foram realizadas as contagens de leveduras totais (CECCATO-ANTONINI, 2010) e leveduras não Saccharomyces (WALTERS; THISELTON, 1953, modificado por MORRIS; EDDY, 1957 apud CECCATO-ANTONINI, 2010).

\subsection{Caracterização do vinho}

Ao término dos processos fermentativos, os vinhos foram caracterizados quanto aos parâmetros: teor alcoólico, medido em ebuliômetro (SILVA et al., 2003); pH por leitura direta em pH-metro digital Digimed DMPH - 2; acidez total titulável através da titulação do vinho com $\mathrm{NaOH} 0,05 \mathrm{~N}$, sendo os resultados expressos em $\mathrm{g} \mathrm{H}_{2} \mathrm{SO}_{4} \cdot \mathrm{L}^{-1}$ (COPERSUCAR, 2001), e açúcares redutores residuais totais (ARRT) pelo método de Lane e Eynon (1934).

\subsection{Destilação do vinho}

Os vinhos provenientes do primeiro e quinto ciclos fermentativos de ambos os tratamentos foram destilados em alambique de cobre com volume útil de 13 litros, contendo caldeira, capitel, alonga e condensador. A fração cabeça correspondeu aos $260 \mathrm{~mL}$ iniciais do destilado (2\% do volume de vinho a ser destilado). Na sequência, foi coletada a fração coração, até a graduação alcoólica atingir 42\%, sendo esta analisada, seguindo as metodologias oficiais, quanto a acidez volátil (em ácido acético), aldeídos (em aldeído acético), ésteres (em acetato de etila), furfural, álcool n-propílico, álcool iso-butílico, álcool iso-amílico e metanol (BRASIL, 2005b).

\subsection{Análise cromatográfica do destilado}

Foram quantificadas por cromatografia em fase gasosa, com detector de ionização de chama (GC-FID), as concentrações de aldeído acético, acetato de etila, furfural, álcoois superiores (álcool propílico, iso-butanol, álcool iso-amílico), ácido acético e metanol das amostras resultantes da mistura dos destilados da primeira e segunda repetição de cada tratamento, provenientes do primeiro e quinto ciclos fermentativos. As análises foram realizadas em cromatógrafo a gás Shimadzu modelo QP-2010 PLUS, com coluna Stabilwax-DA (Crossbond Carbowax polietilenoglicol esterificado, $30 \mathrm{~m} \times 0,18 \mathrm{~mm} \times 0,18 \mu \mathrm{m})$ e detector de ionização de chama (FID). As temperaturas do detector e do injetor foram fixadas em $250^{\circ} \mathrm{C}$ e o modo de injeção foi automático, com divisão de fluxo (split) de 1:25 com um volume de injeção de 1,0 $\mu \mathrm{L}$ da amostra. O fluxo do gás de arraste $\left(\mathrm{H}_{2}\right)$ na coluna foi de $1,5 \mathrm{~mL} \cdot \mathrm{min}^{-1}$ com fluxo total de $42 \mathrm{~mL}$. $\mathrm{min}^{-1}$ e pressão de $252,3 \mathrm{kPa}$. A programação da rampa de temperatura da coluna foi iniciada a $40^{\circ} \mathrm{C}$ (isoterma de $4 \mathrm{~min}$ ), com aumento até $120^{\circ} \mathrm{C}$ a uma taxa de $20^{\circ} \mathrm{C} \cdot \mathrm{min}^{-1}$ (isoterma de $1 \mathrm{~min}$ ) e aumento a $30{ }^{\circ} \mathrm{C} \cdot \mathrm{min}^{-1}$ até $180{ }^{\circ} \mathrm{C}$ (isoterma de $4 \mathrm{~min}$ ) (BORTOLETTO; ALCARDE, 2013).

\subsection{Análise estatística}

Os resultados foram analisados através do Teste F no nível de $5 \%$ de significância e do Teste de Tukey (BANZATTO; KRONKA, 2006), por meio do software Sisvar.

\section{Resultados e discussão}

\subsection{Características físico-químicas e microbiológicas do caldo}

Quanto às características físico-químicas do caldo, não foram observadas diferenças significativas para os parâmetros avaliados, indicando que o tratamento térmico não afetou a qualidade do caldo, podendo, assim, contribuir com o desenvolvimento adequado das leveduras durante o processo fermentativo (Tabela 1). Segundo Oliveira Filho et al. (2016), o aumento nos níveis

Tabela 1. Valores médios de acidez total titulável, sólidos solúveis totais, açúcares redutores totais e pH do caldo de cana tratado termicamente e não tratado'.

\begin{tabular}{|c|c|c|c|c|}
\hline \multirow{2}{*}{ Caldo } & Acidez & SST & ART & \multirow{2}{*}{ pH } \\
\hline & $\left(\mathrm{g} \mathrm{H}_{2} \mathrm{SO}_{4} \cdot \mathrm{L}^{-1}\right)$ & $(\%)$ & $(\%)$ & \\
\hline Tratado & $1,01^{a}$ & $20,30^{a}$ & $18,09^{a}$ & $5,30^{a}$ \\
\hline Não Tratado & $0,95^{\mathrm{a}}$ & $19,50^{a}$ & $17,76^{a}$ & $5,30^{\mathrm{a}}$ \\
\hline Teste F & $3,37^{\mathrm{ns}}$ & $3,81^{\text {ns }}$ & $0,54^{\mathrm{ns}}$ & $2,37^{\text {ns }}$ \\
\hline DMS & 0,07 & 0,85 & 0,95 & 0,10 \\
\hline $\mathrm{CV}$ & 9,44 & 5,64 & 6,94 & 2,45 \\
\hline
\end{tabular}

${ }^{1}$ Médias seguidas de letras iquais na mesma coluna não diferem significativamente pelo Teste de Tukey a 0,05 de probabilidade. ns= não significativo; DMS= Desvio Mínimo Significativo; CV= Coeficiente de Variação; SST= sólidos solúveis totais; ART= açúcares redutores totais. 
Influência do tratamento térmico do caldo de cana no desenvolvimento do processo fermentativo e na composição química da cachaça

Alves, T. M. et al.

de acidez e a redução de açúcares disponíveis no caldo podem comprometer a manutenção do número de células e brotos viáveis de leveduras durante a fermentação alcoólica, resultando em menor produção de álcool.

Os resultados das contagens de microrganismos no caldo demonstraram que o tratamento térmico reduziu a população de bactérias láticas, leveduras totais e leveduras não Saccharomyces, contribuindo com a manutenção de baixas concentrações destes microrganismos no substrato (Tabela 2). Oliveira et al. (2007) também verificaram que a aplicação de tratamento térmico ao caldo de cana possibilitou a redução da população de microrganismos aeróbios psicrotróficos, bactérias láticas e fungos, sem afetar a sua composição físico-química.

A cana-de-açúcar abriga uma diversidade de microrganismos (Acetobacter, Enterobacter, Pseudomonas, Aeromonas, Vibrio, Bacillus, bactérias ácido-láticas e leveduras), sendo a sua população dependente do ambiente de cultivo da planta e das condições operacionais do processo (OLIVEIRA FILHO et al., 2016; SUMAN et al., 2000). Assim, verificou-se que o tratamento térmico do caldo de cana pode ser utilizado para controlar a introdução de diferentes linhagens de microrganismos nas fermentações destinadas à produção de cachaça.

\subsection{Características microbiológicas da fermentação alcoólica}

Os resultados das contagens de microrganismos no fermento reciclado (pé-de-cuba) demonstraram que a população de leveduras totais aumentou até o quarto ciclo, sendo posteriormente reduzida ao final do quinto ciclo fermentativo. Verificou-se que as maiores contagens de leveduras totais ocorreram nas fermentações conduzidas com caldo de cana submetido ao tratamento térmico. Possivelmente, a inativação térmica dos microrganismos naturais do caldo favoreceu a atividade das leveduras no processo devido à maior disponibilidade de nutrientes no mosto (Figura 1).

A recirculação do fermento promoveu um aumento na concentração de leveduras não Saccharomyces após o quarto ciclo para fermentações conduzidas com caldo de cana não tratado termicamente (Figura 2). Possivelmente, a maior concentração de leveduras não Saccharomyces no caldo não tratado $\left(3,4 \times 10^{4} \mathrm{UFC} \cdot \mathrm{mL}^{-1}\right)$ favoreceu o seu crescimento e multiplicação durante a fermentação alcoólica, aumentando o número de células recicladas com o fermento após o quarto ciclo.

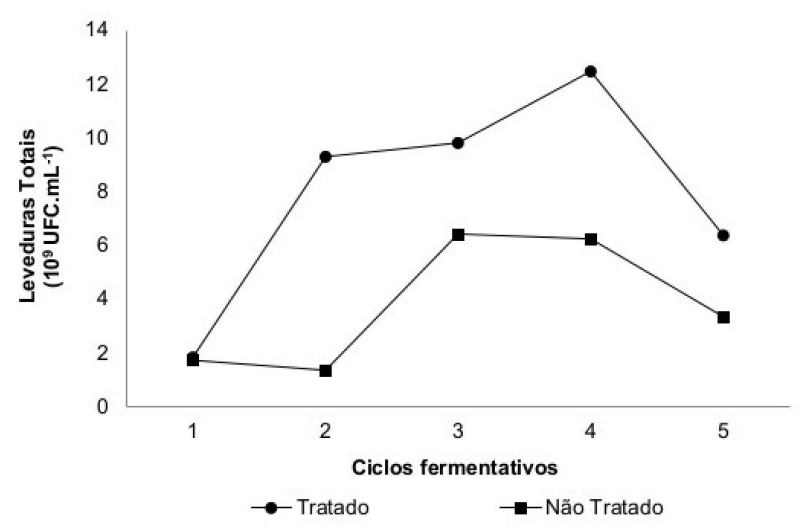

Figura 1. Valores médios para as contagens de leveduras totais no fermento reciclado durante os ciclos fermentativos.

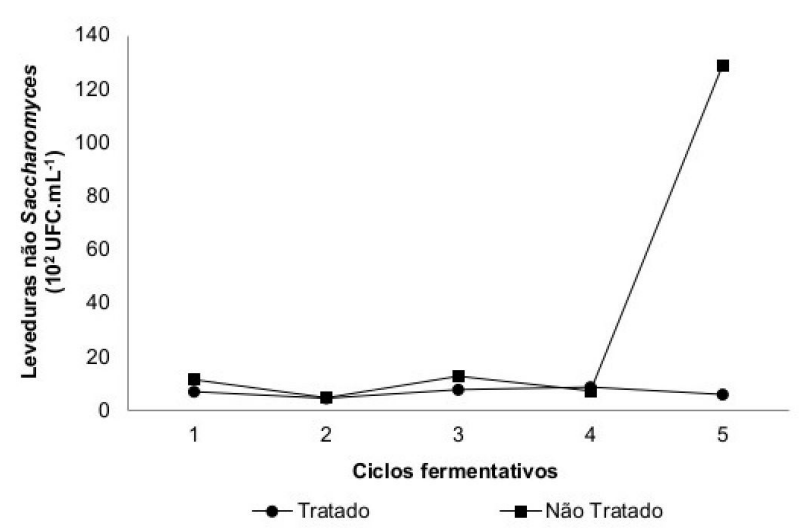

Figura 2. Valores médios para as contagens de leveduras não Saccharomyces no fermento reciclado durante os ciclos fermentativos.

Tabela 2. Bactérias láticas, leveduras totais e leveduras não Saccharomyces presentes no caldo de cana tratado e não tratado termicamente.

\begin{tabular}{rcc}
\hline Análises & Caldo & Resultados \\
Bactérias Láticas & Tratado & $<1 \mathrm{UFC}^{-\mathrm{mL}^{-1}}$ \\
& Não Tratado & $5,2 \times 10^{6} \mathrm{UFC}^{\mathrm{mL}} \mathrm{mL}^{-1}$ \\
Leveduras Totais & Tratado & $<1 \mathrm{UFC}^{\mathrm{mL}} \mathrm{mL}^{-1}$ \\
& Não Tratado & $3,5 \times 10^{5} \mathrm{UFC} \cdot \mathrm{mL}^{-1}$ \\
Leveduras não Saccharomyces & Tratado & $<1 \mathrm{UFC} \cdot \mathrm{mL}^{-1}$ \\
\end{tabular}

UFC. $\mathrm{mL}^{-1}=$ Unidade Formadora de Colônia por mililitro. 
Influência do tratamento térmico do caldo de cana no desenvolvimento do processo fermentativo e na composição química da cachaça

Alves, T. M. et al.

Comportamento semelhante foi observado por Oliveira Filho et al. (2016), ao verificarem que a redução na concentração de leveduras totais no fermento reciclado favoreceu o crescimento de bactérias láticas e leveduras não Saccharomyces, modificando a composição microbiológica do pé-de-cuba.

Segundo Badotti et al. (2010b), a predominância das leveduras no processo é importante; entretanto, altas concentrações de leveduras não Saccharomyces podem comprometer o desempenho das fermentações e a formação dos compostos químicos da cachaça. Assim, verificou-se, no presente estudo, que o tratamento térmico do caldo pode favorecer a atividade das leveduras Saccharomyces cerevisiae, contribuindo com a manutenção de baixas concentrações de microrganismos indesejáveis no processo.

A avaliação microbiológica do processo fermentativo demonstrou que as viabilidades de células e brotos de leveduras, e o índice de brotamento não diferiram estatisticamente para os tratamentos estudados (Figura 3). Entretanto, observou-se uma redução de $8,4 \%$ na viabilidade celular de fermentações conduzidas com caldo de cana não tratado, indicando que o desempenho do processo poderá ser comprometido em ciclos posteriores, pois, para que uma fermentação seja conduzida adequadamente, a porcentagem de células viáveis no processo não deve ser inferior a $85 \%$.

A viabilidade celular permite estabelecer se as leveduras estão sendo submetidas a condições de estresse, sendo um importante parâmetro na avaliação do desempenho operacional (BASSO et al., 2011). O tratamento térmico do caldo forneceu condições mais favoráveis ao desenvolvimento das leveduras no processo, fato este evidenciado através das maiores contagens de leveduras totais recicladas no pé-de-cuba e pela maior porcentagem de células viáveis durante a fermentação do mosto.

\subsection{Características físico-químicas do vinho}

Verificou-se que os valores médios de $\mathrm{pH}$, acidez total titulável, açúcares redutores residuais totais (ARRT) e teor alcoólico não diferiram estatisticamente pelo Teste de Tukey $(p=0,05)$ para os tratamentos avaliados (Tabela 3 ).
Os vinhos destinados à produção de cachaça geralmente possuem uma concentração alcoólica de 7\% a 8\% (OLIVEIRA FILHO et al., 2016; MUTTON et al., 2014), valores estes próximos ao encontrado no presente estudo. Entretanto, verificou-se que a assimilação dos açúcares do meio foi comprometida ao final dos processos fermentativos, devido aos elevados valores de açúcares residuais nos vinhos. Provavelmente, a recirculação das células ao longo dos ciclos ocasionou condições de estresse às leveduras, comprometendo a degradação dos nutrientes do meio.

\subsection{Compostos secundários da cachaça}

Na Tabela 4, estão apresentados os valores obtidos para as concentrações de compostos secundários das cachaças produzidas no primeiro e quinto ciclos fermentativos. Os níveis de acidez volátil, aldeídos, ésteres e dos álcoois metílico, sec-butanol e n-butílico apresentaram-se dentro dos limites estabelecidos pela Legislação (BRASIL, 2005a) para os tratamentos avaliados.

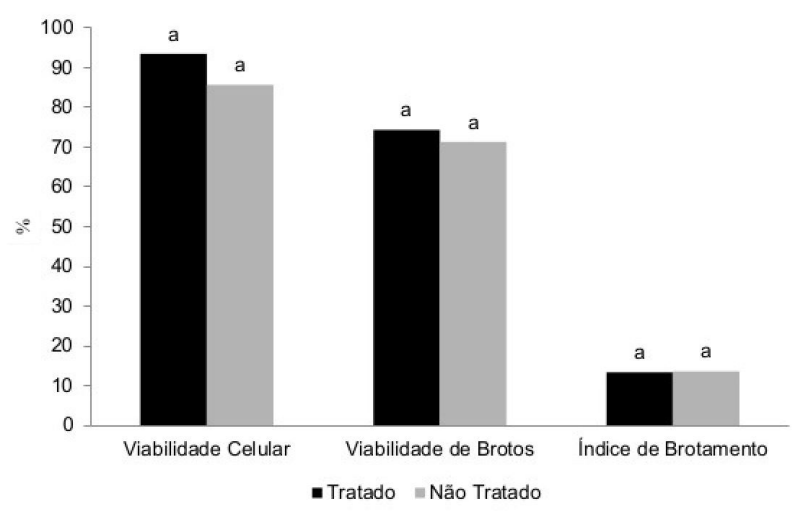

Figura 3. Valores médios para viabilidade de células e brotos e índice de brotamento de leveduras em fermentações conduzidas com caldo de cana tratado e não tratado termicamente. As letras comparam médias entre os tratamentos de cada parâmetro analisado.

Tabela 3. Valores médios de acidez total titulável, teor alcoólico, açúcares redutores residuais totais e pH dos vinhos provenientes de fermentações conduzidas com caldo de cana tratado termicamente e não tratado ${ }^{1}$.

\begin{tabular}{|c|c|c|c|c|}
\hline \multirow{2}{*}{ Caldo } & Acidez & Álcool & ARRT & \multirow{2}{*}{ pH } \\
\hline & $\left(\mathrm{g} \mathrm{H}_{2} \mathrm{SO}_{4} \mathrm{~L}^{-1}\right)$ & $(\%)$ & $(\%)$ & \\
\hline Tratado & $2,81^{a}$ & $7,15^{a}$ & $1,53^{a}$ & $3,81^{a}$ \\
\hline Não Tratado & $2,87^{a}$ & $6,89^{a}$ & $1,60^{a}$ & $3,78^{a}$ \\
\hline Teste F & $0,21^{\text {ns }}$ & $0,54^{\text {ns }}$ & $0,04^{\text {ns }}$ & $0,17^{\mathrm{ns}}$ \\
\hline DMS & 0,26 & 0,73 & 0,75 & 0,15 \\
\hline CV & 12,14 & 13,59 & 62,64 & 5,13 \\
\hline
\end{tabular}

${ }^{1}$ Médias seguidas de letras iguais na mesma coluna não diferem significativamente pelo Teste de Tukey a 0,05 de probabilidade. ns= não significativo; DMS= Desvio Mínimo Significativo; CV= Coeficiente de Variação; ARRT= açúcares redutores residuais totais. 
Influência do tratamento térmico do caldo de cana no desenvolvimento do processo fermentativo e na composição química da cachaça

Alves, T. M. et al.

Tabela 4. Resultados das análises de compostos secundários das amostras de cachaça produzida no primeiro e quinto ciclos fermentativos.

\begin{tabular}{|c|c|c|c|c|c|}
\hline \multirow{2}{*}{$\begin{array}{l}\text { Componentes } \\
\text { Analisados }\end{array}$} & \multicolumn{2}{|c|}{ Caldo Tratado } & \multicolumn{2}{|c|}{ Caldo Não Tratado } & \multirow{2}{*}{$\begin{array}{c}\text { Limites } \\
\text { (BRASIL, 2005a) }\end{array}$} \\
\hline & $1^{\circ} \mathrm{Ciclo}$ & $5^{\circ}$ Ciclo & $1^{\circ} \mathrm{Ciclo}$ & $5^{\circ}$ Ciclo & \\
\hline Acidez volátil* & 22,43 & 28,66 & 18,17 & 38,10 & $0-150$ \\
\hline Aldeídos* & 16,35 & 18,38 & 17,01 & 13,59 & $0-30$ \\
\hline Ésteres* & 6,10 & 13,86 & 8,13 & 22,39 & $0-200$ \\
\hline Álcool metílico* & 3,98 & 5,30 & 4,23 & 5,56 & $0-20$ \\
\hline Álcool sec-butanol* & nd & nd & nd & nd & $0-10$ \\
\hline Álcool n-butílico* & nd & nd & nd & nd & $0-3$ \\
\hline N-propanol* & 15,73 & 18,68 & 18,60 & 17,48 & - \\
\hline |sobutanol* & 75,61 & 14,57 & 87,38 & 13,37 & - \\
\hline Isoamílicos* & 430,81 & 198,91 & 466,62 & 171,41 & - \\
\hline Álcoois superiores* & 522,16 & 232,16 & 572,60 & 202,26 & $0-360$ \\
\hline Furfural $^{*}$ & 2,29 & 7,77 & 0,43 & 7,63 & $0-5$ \\
\hline Coeficiente de congêneres** & 569,32 & 300,82 & 616,34 & 283,96 & $200-650$ \\
\hline
\end{tabular}

${ }^{*} \mathrm{mg} .100 \mathrm{~mL}^{-1}$ álcool anidro; ${ }^{*}$ Coeficiente de congêneres $\left(\mathrm{mg} .100 \mathrm{~mL}^{-1}\right.$ álcool anidro) $=($ acidez volátil + ésteres + aldeídos + furfural + álcoois superiores).

Observou-se que os destilados produzidos a partir de caldo não tratado apresentaram maiores níveis de acidez volátil e ésteres ao final do quinto ciclo, indicando que a presença de microrganismos característicos do caldo favoreceu a produção destes compostos durante a fermentação alcoólica. Segundo Duarte et al. (2013), as leveduras não Saccharomyces, quando em cultivo com Saccharomyces cerevisiae, podem elevar a produção de ácidos voláteis e acetato de etila nas fermentações do caldo de cana.

A concentração dos álcoois superiores (álcool n-propanol, isobutanol e isoamílico) foi superior ao limite estabelecido pela legislação para os destilados (T1 e T2) produzidos no primeiro ciclo fermentativo, enquanto que, no quinto ciclo, os teores destes álcoois foram consideravelmente reduzidos. Oliveira Filho et al. (2016) observaram que a produção destes álcoois é uma característica intrínseca das leveduras Saccharomyces cerevisiae e, provavelmente, a redução destes compostos durante os ciclos fermentativos é decorrente da substituição destas leveduras por linhagens que se desenvolvem durante a fermentação alcoólica.

Os teores de furfural apresentaram-se acima dos limites legais para cachaças produzidas no quinto ciclo fermentativo, independentemente do processo estudado. Provavelmente, a maior concentração de açúcares residuais ao final do quinto ciclo favoreceu a produção de furfural nos destilados. Oliveira Filho et al. (2016) também encontraram uma correlação entre o aumento de açúcares residuais nos vinhos e a formação deste composto na cachaça.

Os congêneres totais foram maiores para os destilados do primeiro ciclo, sendo posteriormente reduzidos no quinto ciclo. Este comportamento é resultado da produção de álcoois superiores, a qual se reduziu durante a condução dos processos fermentativos.

\section{Conclusões}

O tratamento térmico possibilitou a redução da população de bactérias láticas, leveduras totais e leveduras não Saccharomyces do caldo in natura, sem comprometer as suas características físico-químicas.

A utilização de caldo de cana tratado termicamente favoreceu a manutenção de maiores concentrações de células de leveduras nas fermentações alcoólicas, além de reduzir as contagens de leveduras não Saccharomyces no fermento reciclado.

A composição química dos destilados não foi consideravelmente influenciada pela utilização de caldo de cana submetido ao tratamento térmico. Assim, constatou-se que esta operação unitária pode ser utilizada para controlar a carga de microrganismos característicos do caldo de cana, de modo a favorecer a atividade das leveduras previamente inoculadas no processo.

\section{Referências}

BADOTTI, F.; BELLOCH, C.; ROSA, C. A.; BARRIO, E.; QUEROL, A. Physiological and molecular characterization of Saccharomyces cerevisiae cachaça strains isolated from diferente geographic regions in Brazil. World Journal of Microbiology \& Biotechnology, v. 26, n. 4, p. 579-587, 2010a. http://dx.doi.org/10.1007/s11274009-0206-0.

BADOTTI, F.; DÁRIO, M. G.; ROSA, C. A.; STAMBUK, B. U. Caracterização bioquímica e molecular de linhagens de Saccharomyces cerevisiae isoladas de fermentações artesanais de caldo de cana e melado para a produção de cachaça em Florianópolis-SC. Brazilian Journal of Food Technology, 
Influência do tratamento térmico do caldo de cana no desenvolvimento do processo fermentativo e na composição química da cachaça

Alves, T. M. et al.

v. 13, n. 3, p. 205-213, 2010b. http://dx.doi.org/10.4260/ BJFT2010130300027.

BANZATTO, D. A.; KRONKA, S. N. Experimentação agrícola. 4. ed. Jaboticabal: FUNEP, 2006. 237 p.

BARUFFALDI, R.; OLIVEIRA, M. N. Conservação de alimentos por tratamento térmico. In: BARUFFALDI, R.; DE OLIVEIRA, M. N. Fundamentos de tecnologia de alimentos. São Paulo: Atheneu, 1998. cap. 3, p. 27-61.

BASSO, L. C.; AMORIM, H. V.; OLIVEIRA, A. J.; LOPES, M. L. Yeast selection for fuel ethanol production in Brazil. FEMS Yeast Research, v. 8, n. 7, p. 1155-1163, 2008. http://dx.doi. org/10.1111/j.1567-1364.2008.00428.x. PMid:18752628.

BASSO, L. C.; BASSO, T. O.; ROCHA, S. N. Ethanol production in Brazil: the industrial process and its impact on yeast fermentation. Rijeka: Intech, 2011.

BORTOletto, A. M.; AlCARDE, A. R. Congeners in sugar cane spirits aged in casks of different woods. Food Chemistry, v. 139, n. 1-4, p. 695-701, 2013. http://dx.doi.org/10.1016/j. foodchem.2012.12.053. PMid:23561163.

BRASIL. Ministério da Agricultura, Pecuária e Abastecimento. Instrução Normativa $n^{\circ} 13$, de 29 de junho de 2005. Aprova o regulamento Técnico para Fixação dos Padrões de Identidade e Qualidade para Aguardente de Cana e para Cachaça. Diário Oficial [da] República Federativa do Brasil, Brasília, DF, 30 jun. 2005a. Disponível em: <http://www.agricultura.gov.br>. Acesso em: 26 abr. 2017.

BRASIL. Ministério da Agricultura, Pecuária e Abastecimento. Instrução Normativa n ${ }^{\circ} 24$ de 8 de setembro de 2005. Aprova o manual operacional de bebidas e vinagres. Diário Oficial [da] República Federativa do Brasil, Brasília, DF, 20 set. 2005b. Disponivel em: <http://www.agricultura.gov.br>. Acesso em: 20 fev. 2017

CECCATO-ANTONINI, S. R. Microbiologia da fermentação alcoólica: a importância do monitoramento microbiológico em destilarias. São Carlos: EdUFSCar, 2010. 105 p

CONSELHO DOS PRODUTORES DE CANA-DE-AÇÚCAR, AÇÚCAR E ÁLCOOL DO ESTADO DE SÃO PAULO - CONSECANA. Manual de instruções. 3. ed. Piracicaba: CONSECANA, 2006. 112 p. Disponível em: <http://www.orplana.com.br/novosite/ manual_consecana.pdf>. Acesso em: 12 jul. 2016.

COOPERATIVA DE PRODUTORES DE CANA-DE-AÇÚCAR, AÇÚCAR E ÁLCOOL DO ESTADO DE SÃO PAULO - COPERSUCAR. Manual de controle químico da fabricação de açúcar. Piracicaba: COPERSUCAR, 2001. CD-ROM.

DUARTE, W. F.; AMORIM, J. C.; SCHWAN, R. F. The effects of co-culturing non-Saccharomyces yeast with $S$. cerevisiae on the sugar cane spirit (cachaça) fermentation process. Antonie van Leeuwenhoek, v. 103, n. 1, p. 175-194, 2013. http://dx.doi. org/10.1007/s10482-012-9798-8. PMid:22911390.

DUARTE, W. F.; SOUZA, M. V. F.; DIAS, D. R.; SCHWAN, R. F. Effect of co-inoculation of saccharomyces cerevisiae and lactobacillus fermentum on the quality of the distilled sugar cane beverage cachaça. Journal of Food Science, v. 76, n. 9, p. 307-318, 2011. http://dx.doi.org/10.1111/j.1750-3841.2011.02412.x. PMid:22416693.

GOMES, F. C. O.; SILVA, C. L. C.; VIANNA, C. R.; LACERDA, I. C. A.; BORELLI, B. M.; NUNES, A. C.; FRANCO, G. R.; MOURÃO, M. M.; ROSA, C. A. Identification of lactic acid bacteria associated with traditional cachaça fermentations. Brazilian Journal of Microbiology, v. 41, n. 2, p. 486-492, 2010. http://dx.doi. org/10.1590/S1517-83822010000200031. PMid:24031520.

LANE, J. H.; EYNON, L. Determination of reducing sugars by Fehling solution with methylene blue indicator. London: Normam Roger, 1934. 8 p

MUTTON, M. J. R.; OLIVEIRA FILHO, J. H.; COSTA, G. H. G.; ROVIERO, J. P.; FREITA, L. A. Green and brown propolis: efficient natural biocides for the control of bacterial contamination of alcoholic fermentation of distilled beverage. Food Science and Technology (Campinas), v. 34, n. 4, p. 767-772, 2014. http:// dx.doi.org/10.1590/1678-457X.6469

OLIVEIRA FILHO, J. H.; BORTOLETtO, A. M.; ALCARDE, A. R. Qualidade pós-colheita de colmos de cana armazenados e seus reflexos na produção de cachaça. Brazilian Journal of Food Technology, v. 19, n. 1, p. 1-9, 2016

OLIVEIRA, A. C. G.; SPOTO, M. H. F.; CANNIATTI-BRAZACA, S. G.; SOUSA, C. P.; GALLO, C. R. Efeitos do processamento térmico e da radiação gama na conservação de caldo de cana puro e adicionado de suco de frutas. Ciência e Tecnologia de Alimentos, v. 27, n. 4, p. 863-873, 2007.

SILVA, L. F. L. F.; BERNADINO, C. D.; RÉ, F. E.; FURTADO, C. $H$. F.; AMORIM, H. V. Métodos analíticos para o controle da produção de açúcar e álcool. 3. ed. Piracicaba: Fermentec, 2003. $126 \mathrm{p}$

SOUZA, M. A. C.; MUTTON, M. J. R. Floculação de leveduras por Lactobacillus fermentum em processos industriais de fermentação alcoólica avaliada por técnica fotométrica. Ciência e Agrotecnologia. Lavras, v. 28, n. 4, p. 893-898, 2004.

SUMAN, A.; SOLOMON, S.; YADAV, D. V.; GAUR, A.; SINGH, M. Post-harvest loss in sugarcane quality due to endophytic microrganisms. Sugar Tech, v. 2, n. 4, p. 21-25, 2000. http:// dx.doi.org/10.1007/BF02995581. 